\title{
IDENTIFICATION OF SELF POSITION AND BASIC ATTITUDE OF COUNSELORS BY SEMAR TEXT (Study Analysis of Hermeneutik Gadamerian)
}

\author{
Galang Surya Gumilang \\ Program Studi Bimbingan dan Konseling \\ Universitas Nusantara PGRI Kediri \\ galangsuryagumilang@yahoo.com
}

\begin{abstract}
The purpose of this study are to know: (1) self-position of counselor which was adopted from the text of Semar, (2) The basic attitude which was adopting from the text of Semar, (3) The technic for communicating base attitude of counselor are using the metaphor in counseling. This research uses the Qualitative approach by Gadamerian hermeneutic method. Gadamerian hermeneutics is a kind of objective hermeneutic research (Objectivist hermeneutics). Gadamerian hermeneutics unifying thought is contained in a hermeneutic circle pattern. The circle consists of a pattern of up and down between the parts (part) and overall (whole) to understand the meaning of a text. The Data of research are including two texts such as what and who Semar is? (Mulyono, 1978) and Semar as spiritual world of Javanese (Sumukti, 2006), data of interview with Ki Manteb Sudarsono, Ki Purbo Asmoro, S.Kar., M.Hum and Dra. Sri Saptaningsih, MM and data watching the video of wayang. The result of research show that self-position of counselor which was adopted from the text of Semar are: (1) advicer, (2) motivator, (3) deterrent, (4) servant. The basic attitude which was adopting from the text of Semar are: (1) hospitable, (2) wise, (3) honest, (4) care. The technic for communicating basic attitude of counselor are using advice technique.
\end{abstract}

Keywords: position counselor, the basic attitude of counselor, Semar text

\section{PENDAHULUAN}

Dunia internasional mengakui wayang sebagai seni pertunjukan asli dari Indonesia yang memiliki nilai-nilai luhur. Wayang tidak hanya memiliki nilai estetika yang tinggi, tetapi juga menggambarkan karakter-karakter tokoh-tokoh pewayangan. Wayang diakui oleh perserikatan bangsa-bangsa (PBB) melalui The United Nations Educational Scientific and Cultural Organization (UNESCO) mengeluarkan penghargaan berupa sertifikat tertanggal 7 November 2003 yang isinya menyatakan bahwa wayang sebagai Masterpiece of The Oral and Intangible of Humanity (karya agung budaya dunia).

Di Indonesia, wayang merupakan bentuk seni pertunjukan yang penuh makna. Wayang juga diartikan sebagai bayangan yang artinya yaitu wayang dianggap dapat memberikan petunjuk bagi orang hidup. Cerita wayang juga mengandung kearifan lokal, nilai-nilai, karakter yang luhur dan ajaran kebijaksanaan serta yang relevan untuk diaplikasikan dalam kehidupan seharihari.

Salah satu tokoh wayang yang paling digemari oleh masyarakat khususnya masyarakat Jawa yaitu Semar. Menurut Sumukti (2006: 20-21) ada dua versi utama yang menceritakan asal-usul Semar. Pertama, mengatakan bahwa surga (langit) dan bumi dikuasai oleh Sang Hyang Wenang. Sang Hyang Wenang berputra satu bernama Sang Hyang Tunggal. Sang Hyang Tunggal memperistri Dewa Rekawati, putri kepiting raksasa yang bernama Rekatama. Pada suatu hari Rekawati bertelur dan seketika itu telur itu 
terbang ke langit ke hadapan Sang Hyang Wenang. Setiba dihadapan Sang Hyang Wenang, telur tersebut menetas sendiri, dan terwujudlah tiga makhluk antropomorfis yang muncul dari kulit telur, dinamai Tejamantri, lalu tampaklah Ismaya yang berasal dari putih telur dan Manikmaya terjadi dari kuning telur itu.

Sumukti (2006: 21) versi kedua menyebutkan bahwa alam semesta muncul sebagai sesuatu yang tercipta sekaligus. Diceritakan bahwa sebutir telur yang dipegang Sang Hyang Wenang menetas dengan sendirinya, dan tampaklah langit, bumi dan cahaya atau teja, serta dua makhluk anthropomorphis, Manik dan Maya. Kalau versi pertama dan kedua dibandingkan, ada persamaannya. Ismaya dari versi pertama dan Maya dari versi kedua, terjadi dari putih telur, dan keduanya bertugas memelihara bumi. Manikmaya dan Manik merupakan transformasi dari kuning telur, dan keduanya menjadi raja para dewa di surga. Dalam kedua versi itu Manikmaya dan Manik menjadi Bathara Guru, yang keturunannya tersebar di surga dan di bumi, sedangkan Ismaya dan Maya dinamakan Semar dan dijadikan pelindung bumi (dunia). Jelas disini bahwa Semar merupakan tokoh dominan di alam semesta dan sebagai pelindung bumi erat hubungannya dengan penduduk bumi.

Berdasarkan paparan pra-lapangan wawancara dengan dalang sekaligus dosen ISI Surakarta yaitu Ki Purbo Asmoro S.Kar, M.Hum mengatakan bahwa Semar muncul pada kisah Sudamala dari zaman majapahit sebagai trah dewa yang memilih menjadi abdi yang mengemong satria yang memberikan nasihat dan menjadi motivator bagi para Pandawa untuk mengingatkan ketika menyimpang dan kembali ke jalan kebenaran. Hal tersebut juga ditegaskan oleh dalang Ki Manteb Sudarsono yang mengatakan bahwa bahwa Semar asli dari Indonesia sebagai keturunan dewa yang suci dari hati nurani yang paling dalam yang menjadi abdi bagi Pandawa dan bersifat misterius karena memiliki dua bentuk yaitu laki-laki atau perempuan.

Semar tidak terlepas dari peran konselor. Jika dalam pewayangan, Semar abdi, pamong, dan pengayom bagi para ksatria serta sebagai orang tua dalam punakawan dan para ksatria dan didukung oleh penyataan Ki Manteb Sudarsono, bahwa siapa saja yang di bimbing oleh Semar, pasti akan menjadi lebih baik lagi. Hal tersebut tidak lepas dari tugas seorang konselor yaitu memberikan bimbingan kepada konseli serta mengarahkan untuk perubahan yang lebih baik. Akan tetapi, Masih banyak konselor yang tidak memberikan pelayanan yang baik kepada konseli.

Hasil pra-lapangan wawancara dengan salah satu konselor sekolah di kota Surakarta yang mengatakan bahwa bahwa konselor harus memberikan layanan konseling secara berkelanjutan. Tetapi kenyataan di lapangan menyebutkan bahwa guru BK kurang memberikan pelayanan konseling karena berbagai macam kendala yang meliputi guru pendiam, cuek, kurang terbuka, berorientasi oleh uang, kurang sabar, kurang tulus, serta kurang monitoring perkembangan konseli secara berkelanjutan. Kendala seperti itulah yang membuat konselor kurang memiliki pribadi altruistik yaitu mengutamakan kepentingan konseli dalam memberikan layanan konseling secara prima dan berkelanjutan.

Konseling adalah sebuah " an altruistic and noble profession" (Gladding, 2009: 34). Pada umumnya profesi ini menarik orang-orang yang peduli terhadap orang lain, ramah, bersahabat, dan sensitif. Orang yang bercita-cita menjadi seorang konselor sebaiknya mengamati diri sendiri dulu, sebelum benar-benar berkomitmen 
terhadap profesi ini. Shertzer \& Stone (1980: 8-9) menyatakan ciri-ciri "helping relationship" yaitu (1) helping relationship adalah penuh makna dan bermanfaat, (2) afeksi sangat mencolok dalam "helping relationship", (3) keutuhan pribadi tampil atau terjadi dalam "helping relationship" (4) "helping relationship" terbentuk melalui kesepakatan bersama individuindividu yang terlibat, (5) saling hubungan terjalin karena individu yang hendak dibantu membutuhkan informasi, pelajaran, nasehat, bantuan, pemahaman dan perhatian dari orang lain, (6) "helping relationship" dilangsungkan melalui komunikasi dan interaksi, (7) struktur yang jelas dalam "helping relationship", (8) upaya yang bersifat kerja sama menandai profesi bantuan, (9) orang-orang dalam "helping relationship" dapat dengan mudah ditemui atau didekati (approachable), dan (10) perubahan merupakan tujuan "helping relationship".

\section{METODE}

Penelitian ini menggunakan pendekatan kualitatif dengan metode hermeneutik. Menurut Palmer (1969: 8) menyatakan hermeneutika adalah studi pemahaman, khususnya tugas pemahaman teks.Mappiare (2013: 118) menjelaskan hermeneutika (Hika) harus mempunyai tujuan yang lebih dari tujuan negasi untuk mengatasi hambatan dalam cara menemukan kembali tujuan asli penulis. Tipe riset hermeneutika melibatkan kiat mencoba suatu teks sehingga maksud dan makna di balik pengalaman yaitu butirbutir peristiwa dan makna-makna dipahami secara penuh.

Secara spesifik, peneliti menggunakan hermeneutik Gadamerian dalam menemukan makna di balik karakter Semar. Hermeneutik merupakan sebuah disiplin ilmu dalam menafsirkan makna yang terdapat di dalam teks. Perkembangan awal hermeneutik digunakan untuk menginterpretasikan kitab injil (bible) (Mulyono, 2013: 20-21; Palmer, 1969: 36). Perkembangan selanjutnya digunakan untuk menginterpretasikan tindakan sosial dan karya sastra.

Alvesson dan Skoldberg (2000: 5658 ) riset hermeneutik dibagi menjadi dua yaitu hermeneutik objektif (objectivst hermeneutics) dan hermeneutik alektik (alectic hermeneutics). Tataran ini menjelaskan bahwa hermeneutik Gadamerian merupakan jenis riset hermeneutik objektif (objectivist hermeneutics). Pokok pemikiran hermeneutika Gadamerian yaitu terdapat pada sebuah pola lingkaran hermeneutik. Lingkaran tersebut terdiri dari pola naik turun antara bagian (part) dan keseluruhan (whole) untuk memahami makna dalam sebuah teks. Menurut Rahardjo (2008) bagian (part) akan mengubah pemahaman kita pada keseluruhan dan sebaliknya pengubahan pada pemahaman kita terhadap keseluruhan (whole) akan mengubah pemahaman kita pada bagian dan seterusnya. Lingkaran hermeneutik sering digambarkan sebagai logika antara part dan whole dalam Gambar 1

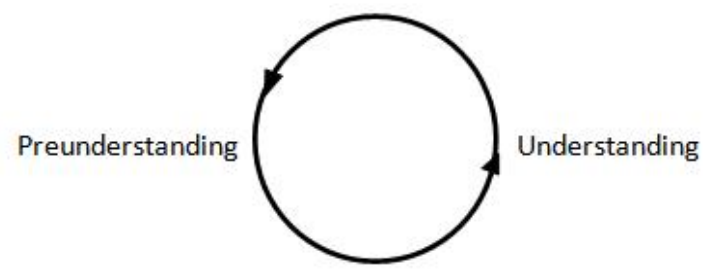

Gambar 1. Lingkaran Hemeneutik Gadamerian (Alvesson dan Skoldberg, 2000: 57)

Gambar diatas menunjukkan bahwa hermeneutik Gadamerian sebagai metode penafsiran teks masa lalu agar dapar dipahami pada masa sekarang melalui siklus antara part dan whole dengan menggunakan bahasa sebagai alat utama dalam menafsirkan makna teks. 


\section{HASIL DAN PEMBAHASAN}

Hasil penelitian menunjukkan bahwa posisi diri konselor dengan diadopsi dari teks Semar yaitu (1) penasehat, (2) penyemangat, (3) pencegah, (4) pelayan.

Tabel 3.2Posisi Diri Konselor Dengan Diadopsi Dari Teks Semar

\begin{tabular}{lll}
\hline No & \multicolumn{1}{c}{ Data Teks } & \multicolumn{1}{c}{ Kode $^{*}$} \\
\hline $\mathbf{1}$ & Penasehat & $\begin{array}{l}\text { ASS Pen a/ SDBOJ } \\
\text { Pen a/ SDBOJ Pen m }\end{array}$ \\
\hline $\mathbf{2}$ & Penyemangat & ASS Peny b \\
\hline 3 & Pencegah & $\begin{array}{l}\text { ASS Prev c/ ASS Prev } \\
\text { d }\end{array}$ \\
\hline 4 & Pelayan & $\begin{array}{l}\text { ASS Pel i/ SDBOJ Pel } \\
\text { b/ SDBOJ Pel d }\end{array}$ \\
\hline
\end{tabular}

Catatan:

* Huruf pada kolom kode menjelaskan nomor urut dalam teks Semar
Sikap dasar konselor dengan diadopsi dari teks Semar yaitu (1) ramah, (2) bijaksana, (3) jujur, (4) peduli.

Tabel 3.3 Sikap Dasar Konselor Dengan Diadopsi Dari Teks Semar

\begin{tabular}{lll}
\hline No & Data Teks & \multicolumn{1}{c}{ Kode $^{*}$} \\
\hline 1 & Ramah & ASS Ram j \\
\hline 2 & Bijaksana & $\begin{array}{l}\text { SDBOJ Bij e/ SDBOJ } \\
\text { Bij k/ SDBOJ Bij l/ } \\
\text { SDBOJ Bij o }\end{array}$ \\
\hline 3 & Jujur & $\begin{array}{l}\text { SDBOJ Juj g/ SDBOJ } \\
\text { Juj h }\end{array}$ \\
\hline 4 & Peduli & $\begin{array}{l}\text { ASS Ped e/ SDBOJ Ped } \\
\text { f }\end{array}$ \\
\hline
\end{tabular}

Catatan:

* Hurufpadakolomkodemenjelaskann omorurut dalam teks Semar

Teknik untuk mengomunikasikan sikap dasar konselor yaitu menggunakan teknik metafora dalam konseling berbentuk Wejangan/pepatah Jawa (Lihat Tabel 3.4).

Tabel 3.4 Teknik Untuk Mengomunikasikan Sikap Dasar Konselor.

\begin{tabular}{|c|c|c|c|}
\hline No & $\begin{array}{c}\text { Wejangan/nasihat } \\
\text { Semar }\end{array}$ & Deskripsi & Makna \\
\hline 1 & $\begin{array}{l}\text { Mbegegeg ugeg-ugeg } \\
\text { hemel hemel sak } \\
\text { dulita(diam, } \\
\text { bergerak/berusaha, } \\
\text { makan, walaupun sedikit, } \\
\text { abadi). }\end{array}$ & $\begin{array}{l}\text { Wejangan/nasihat tersebut } \\
\text { dituturkan Semar ketika } \\
\text { pertama kalinya muncul } \\
\text { dalam cerita lakon } \\
\text { pewayangan. }\end{array}$ & $\begin{array}{l}\text { Siapa yang mau berusaha } \\
\text { meskipun hasilnya tidak } \\
\text { seberapa (sedikit) lebih baik } \\
\text { daripada tidak berusaha sama } \\
\text { sekali. }\end{array}$ \\
\hline 2 & $\begin{array}{l}\text { Ngudi laku utama kanthi } \\
\text { sentosa ing budi(ingin } \\
\text { melakukan yang baik } \\
\text { harus disertai budi yang } \\
\text { kuat). }\end{array}$ & $\begin{array}{l}\text { Wejangan/nasihat tersebut } \\
\text { dituturkan Semar untuk } \\
\text { memberikan motivasi } \\
\text { kepada Pandawa khususnya } \\
\text { Arjuna di kala bingung } \\
\text { dalam mengambil } \\
\text { keputusan. }\end{array}$ & $\begin{array}{l}\text { Siapa yang menebar kebaikan } \\
\text { harus diimbangi dengan akhlak } \\
\text { yang baik pula. }\end{array}$ \\
\hline 3 & $\begin{array}{l}\text { Wong cilik ora sugih } \\
\text { bandha nanging sugih } \\
\text { rasa(orang kecil/rakyat } \\
\text { tidak kaya harta tetapi } \\
\text { kaya hati). }\end{array}$ & $\begin{array}{l}\text { Wejangan/nasihat tersebut } \\
\text { dituturkan Semar ketika } \\
\text { Pandawa dan ibu Kunthi } \\
\text { ketika Nakula dan Sadewa } \\
\text { kelaparan. Semar } \\
\text { menjelaskan bahwa Satria } \\
\text { itu harus kaya hati } \\
\text { ketimbang kaya harta. } \\
\text { Satria harus bisa menahan }\end{array}$ & $\begin{array}{l}\text { Kaya harta bukan merupakan } \\
\text { jaminan kebahagiaan dan bisa } \\
\text { sirna sewaktu-waktu. Tetapi } \\
\text { kaya rasa (ilmu) tetap abadi dan } \\
\text { bermanfaat bagi orang lain. }\end{array}$ \\
\hline
\end{tabular}




\begin{tabular}{|c|c|c|c|}
\hline No & $\begin{array}{l}\text { Wejangan/nasihat } \\
\text { Semar }\end{array}$ & Deskripsi & Makna \\
\hline & & $\begin{array}{l}\text { lapar, haus, serta tidak } \\
\text { cengeng. }\end{array}$ & \\
\hline 4 & $\begin{array}{l}\text { Ngunduh wohing } \\
\text { pakarti(seseorang akan } \\
\text { dapat balasan setimpal } \\
\text { karena tingkah lakunya). }\end{array}$ & $\begin{array}{l}\text { Wejangan/nasihat tersebut } \\
\text { dituturkan Semar ketika ada } \\
\text { Satria (Pandawa) yang } \\
\text { melakukan penyimpangan. } \\
\text { Jika melakukan perbuatan } \\
\text { yang tidak baik, maka di } \\
\text { kemudian hari kita pun } \\
\text { akan mendapatkan sesuatu } \\
\text { yang tidak baik. }\end{array}$ & $\begin{array}{l}\text { Perilaku sebagai ilustrasi bagi } \\
\text { pribadi seseorang. }\end{array}$ \\
\hline 5 & $\begin{array}{l}\text { Memayu hayuning jiwa, } \\
\text { memayu hayuning } \\
\text { keluwarga, memayu } \\
\text { hayuning sasama, dan } \\
\text { memayu hayuning } \\
\text { bawana(piawai menata } \\
\text { diri, piawai menata } \\
\text { keluarga, piawai menata } \\
\text { golongan/kelompok, dan } \\
\text { piawai menata } \\
\text { masyarakat). }\end{array}$ & $\begin{array}{l}\text { Wejangan/nasihat tersebut } \\
\text { dituturkan Semar untuk } \\
\text { mengajak Pandawa } \\
\text { bagaimana cara menjalani } \\
\text { hidup yang baik dengan } \\
\text { dimulai dari diri sendiri } \\
\text { sebelum melihat ke orang } \\
\text { lain. }\end{array}$ & $\begin{array}{l}\text { Instrospeksi diri sendirisebelum } \\
\text { menata (memikirkan) orang lain. }\end{array}$ \\
\hline 6 & $\begin{array}{l}\text { Tumindak kanthi duga } \\
\text { lan prayoga (bertindak } \\
\text { harus berpikir dan } \\
\text { dipertimbangkan). }\end{array}$ & $\begin{array}{l}\text { Wejangan/nasihat tersebut } \\
\text { dituturkan Semar untuk } \\
\text { mengajarkan kebijaksanaan } \\
\text { kepada Pandawa ketika } \\
\text { mengambil suatu } \\
\text { keputusan. }\end{array}$ & $\begin{array}{l}\text { Jangan gegabah sebelum } \\
\text { melakukan sesuatu. Sebelum } \\
\text { mengambil keputusan, perlu } \\
\text { dipikirkan matang-matang biar } \\
\text { hasilnya maksimal. }\end{array}$ \\
\hline 7 & $\begin{array}{l}\text { Rame ing gawe sepi ing } \\
\text { pamrih, memayu } \\
\text { hayuning bawana } \\
\text { (banyak berkarya tanpa } \\
\text { menuntut balas jasa, } \\
\text { membangun kebahagiaan } \\
\text { dunia). }\end{array}$ & $\begin{array}{l}\text { Wejangan/nasihat tersebut } \\
\text { dituturkan Semar untuk } \\
\text { mengajarkan keikhlasan } \\
\text { kepada Pandawa dalam } \\
\text { memberikan sesuatu kepada } \\
\text { orang lain. }\end{array}$ & $\begin{array}{l}\text { Ikhlas dalam memberikan segala } \\
\text { sesuatu yang terbaik untuk } \\
\text { kemaslahatan umat. }\end{array}$ \\
\hline 8 & $\begin{array}{l}\text { Mulat salira, tansah eling } \\
\text { lan waspada (mawas diri } \\
\text { selalu ingat dan waspada). }\end{array}$ & $\begin{array}{l}\text { Wejangan/nasihat tersebut } \\
\text { dituturkan Semar ketika } \\
\text { mencegah Pandawa } \\
\text { (Werkudara/Bima) jika } \\
\text { melakukan penyimpangan } \\
\text { dan tidak bisa mengontrol } \\
\text { emosinya saat menghadapi } \\
\text { satria angkara murka } \\
\text { (Kurawa). }\end{array}$ & $\begin{array}{l}\text { Di dunia ini manusia harus } \\
\text { berhati-hati dan ingat bahwa } \\
\text { Allah SWT selalu mengawasi } \\
\text { setiap saat. }\end{array}$ \\
\hline 9 & $\begin{array}{l}\text { Sing sapa ngudi } \\
\text { kautaman, upayanen } \\
\text { ngelmu kang karya } \\
\text { tentreming ati (barang } \\
\text { siapa mencari keutamaan, } \\
\text { usahakan ilmu yang dapat } \\
\text { menentramkan hati). }\end{array}$ & $\begin{array}{l}\text { Wejangan/nasihat tersebut } \\
\text { dituturkan Semar untuk } \\
\text { mengajarkan kepedulian } \\
\text { kepada Pandawa saat } \\
\text { menuntut ilmu kemudian } \\
\text { mengamalkannya dalam } \\
\text { kepada masyarakat. }\end{array}$ & $\begin{array}{l}\text { Setiap orang diwajibkan } \\
\text { menuntut ilmu serta } \\
\text { mengamalkannya secara positif } \\
\text { dalam kehidupan sehari-hari. }\end{array}$ \\
\hline
\end{tabular}




\begin{tabular}{|c|c|c|c|}
\hline No & $\begin{array}{l}\text { Wejangan/nasihat } \\
\text { Semar }\end{array}$ & Deskripsi & Makna \\
\hline 10 & $\begin{array}{l}\text { Sing sapa mung arep } \\
\text { gawe seriking liyan, kuwi } \\
\text { uga arep nemahi cilaka } \\
\text { (barang siapa yang hanya } \\
\text { akan membuat sakit hati } \\
\text { orang lain, itu juga akan } \\
\text { celaka). }\end{array}$ & $\begin{array}{l}\text { Wejangan/nasihat tersebut } \\
\text { dituturkan Semar untuk } \\
\text { mengajarkan kejujuran } \\
\text { kepada Pandawa agar selalu } \\
\text { berbuat baik kepada orang } \\
\text { lain yang menyakitinya. }\end{array}$ & $\begin{array}{l}\text { Maju tanpa mennyakiti orang } \\
\text { lain, naik tinggi tanpa } \\
\text { menjatuhkan orang lain. }\end{array}$ \\
\hline
\end{tabular}

\section{Unsur-unsur dan Deskripsi Posisi Diri Konselor Dengan Diadopsi Dari Teks Semar}

\section{Penasehat}

Doyle (1998: 230) menjelaskan peran menasihati digunakan ketika konselor ingin membantu konseli memikirkan solusi untuk masalah, merenungkan ide yang diungkapkan dan mungkin saja bisa digunakan, serta merencanakan tindakan atau mengembangkan pilihan-pilihan yang ada. Peran ini juga dapat dibicarakan melalui diskusi yaitu: meminta konseli untuk menyebutkan setiap saran yang telah ia dengar dan yang berhubungan dengan masalah yang sedang dihadapi untuk mengenalkan dan menguji saran secara obyektif. Peran ini juga berlaku ketika konselor merasa bahwa masalah ini perlu dialih tangankan kepada ahli lain yang lebih profesional.

Sebagai konselor harus hati-hati di setiap memberikan saran kepada konseli, karena sangat berarti bagi konselisebagai kerangka acuan, dan praktis untuk konseli. Selanjutnya, rekomendasi yang harus dibuat hanya bila konselor pikir itu perlu untuk memajukan proses konseling dan di mana konselor hanya memiliki beberapa pengetahuan yang jelas dan memliki keahlian (Benjamin, 1987; Cormier \& Cormier, 1991; Epstein, 1985 dalam Doyle, 1998: 231).

\section{Penyemangat}

Menurut Mc. Donald (dalam Sardiman, 2011: 73-74) motivasi adalah perubahan dengan munculnya felling dan didahului dengan tanggapan terhadap adanya tujuan. Dari pengertian yang dikemukakan ini mengandung tiga elemen penting:

a. Motivasi itu mengawali terjadinya perubahan energi pada diri setiap individu manusia. Perkembangan motivasi akan membawa beberapa perubahan energi di dalam sistem neurophysiological yang ada pada organisme manusia. Karena menyangkut perubahan energi manusia (walaupun motivasi itu muncul dari dalam diri manusia), penampakannya akan menyangkut kegiatan fisik manusia.

b. Motivasi ditandai dengan munculnya rasa/fellin, afeksi seseorang. Dalam hal ini motivasi relevan dengan persoalanpersoalan kejiwaan, afeksi dan emosi yang dapat menentukan tingkah-laku manusia.

c. Motivasi akan dirangsang karena adanya tujuan. Jadi motivasi dalam hal ini sebenarnya merupakan respons dari suatu aksi, yakni tujuan. Motivasi memang muncul dari dalam diri manusia, tetapi kemunculannya karena terangsang/terdorong oleh adanya unsur lain, dalam hal ini adalah tujuan. Tujuan ini akan menyangkut soal kebutuhan.

Menurut Maslow (dalam Jarvis: 2015: 94) mengembangkan teori manusia yang tujuannya menjelaskan segala jenis kebutuhan manusia dan mengurutkannya menurut tingkat prioritas manusia dalam pemenuhannya. 


\section{Pencegah}

Berkaitan dengan upaya konselor untuk senantiasa mengantisipasi berbagai masalah yang mungkin terjadi dan berupaya untuk mencegahnya, supaya tidak dialami oleh konseli (Hikmawati, 2014: 18). Melalui fungsi ini, konselor meemberikan bimbingan kepada konseli tentang cara menghindarkan diri dari perbuatan atau kegiatan yang membahayakan dirinya.

Menurut Asmani (2010: 58) juga menjelaskan bahwa dalam fungsi pencegahan ini, layanan yang diberikan berupa bantuan bagi para siswa agar terhindar dari berbagai masalah yang dapat menghambat perkembangannya.

\section{Pelayan}

Pelayanan bimbingan dan konseling di sekolah/madrasah merupakan usaha untuk membantu peserta didik dalam pengembangan kehidupan pribadi, kehidupan sosial, kegiatan belajar, serta perencanaan dan pengembangan karier (Asmani, 2010: 133-134)

Hikmawati (2014: 21) pelayanan bimbingan dan konseling memfasilitasi pengembangan peserta didik, secara individual, kelompok, dan/atau klasikal sesuai dengan kebutuhan, potensi, bakat, minat, perkembangan, kondisi, serta peluang-peluang yang dimiliki.

Konselor sebagai fasilitator dan reflektor. Disebut fasilitator karena konselor memfasilitasi atau mengakomodasi konseli mencapai pemahaman diri. Disebut reflektor karena konselor mengklarifikasi dan memantulkan kembali pada konseli perasaan dan sikap yang diekspresikannya terhadap konselor sebagai representasi orang lain (Gibson \& Mitchell, 2011: 216).

Konselor sebagai pribadi yang altruistik. Mappiare (2011: 102) pribadi yang altruistik ditandai dengan kesediaan berkorban (waktu, tenaga, dan mungkin materi) untuk kepentingan kebahagiaan atau kesenangan orang lain. Konselor sebagai helping profesion harus melayani konselinya dengan ikhlas, ramah, serta bisa menjaga konfidensialitas dari konseli.

Rogers (1957: 95-103) konselor harus berhati-hati dalam melakukan diagnosis, memaknai pernyataan yang diungkapkan oleh konseli, dan memahami konseli secara utuh. Kehati-hatian yang ditunjukkan konselor ditampilkan untuk menghindari adanya kesalahan persepsi yang menyebabkan konseli merasa tidak nyaman berada dalam situasi konseling.

\section{Unsur-unsur dan Deskripsi Sikap Dasar Konselor Dengan Diadopsi Dari Teks Semar}

\section{Ramah}

Pribadi yang ramah merupakan penerimaan tanpa syarat. Mappiare (2011: 105) menjelaskan bahwa Penerimaan sebagai salah satu sikap dasar konselor mengacu pada kesediaan konselor memiliki penghargaan tanpa menggunakan standar ukuran prasyaratan tertentu terhadap individu sebagai manusia atau pribadi yang utuh.

Komalasari, dkk. (2011: 268) acceptance adalah menunjukkan penghargaan yang spontan terhadap konseli, dan menerimanya sebagai individu yang berbeda dengan konselor. Perbedaan antara konselor dapat terjadi pada nilanilai, persepsi diri, maupun pengalamanpengalaman hidupnya. Penerimaan ini bertujuan membangun hubungan terapeutik menjadi lebih konstruktif.

\section{Bijaksana}

Dalam bimbingan dan konseling, konselor yang bijaksana adalah konselor sadar dirinya sebagai seorang helping prefession. Self awarenes sendiri 
merupakan sikap dasar yang kemudian membentuk sikap-sikap lainnya. Maka seorang konselor harus mampu menjawab jelas pertanyaan siapakah saya?, apakah yang penting bagi saya?, apakah signifikansi sosial bagi saya apa yang saya lakukan dan mengapa saya menjadi seorang helper/konselor? (Mappiare, 2011: 100).

Konselor juga bijaksana dalam menerima konseli yang berlatar belakang budaya yang berbeda. Ahmed, dkk (2011: 112) bahwa konselor tidak boleh menggunakan stereotypes, menilai, dan memaksakan nilai yang dipegang oleh konselor kepada konseli. Konselor harus memiliki kesadaran dan rasa menghargai akan adanya perbedaan budaya antara konselor dan konseli.

\section{Jujur}

Mappiare (2011: 109) kesejatian (Authenticity) pada dasarnya menunjuk pada keselarasan (harmoni) yang mesti ada dalam pikiran dan perasaan konselor dengan apa yang terungkap melalui perbuatan ataupun ucapan verbalnya. Beliau juga menjelaskan keterbukaan (Openess atau disclosure) pada konselor merupakan kualitas pribadi yang dapat disebut sebagai cara konselor mengungkapkan kesejatiannya.

Congruence (kongruensi) adalah ketulusan, realness (tidak berpura-pura), keterbukaan, transparansi, dan presence (kesadaran) (Nelson-Jones, 2011: 109). Gladding (2009: 209) kesejatian merupakan kondisi transparan di dalam hubungan terapi dengan menghilangkan aturan penghalang. Hal ini adalah kesiapan konselor untuk mengesampingkan kepedulian dan kesibukan pribadi dan ada serta terbuka di dalam hubungan dengan konseli.

Martinez (dalam Rivera, dkk; 2006: 1-9) yang menyatakan bahwa hubungan konseling yang efektif adalah hubungan konseling yang memperhitungkan perbedaan budaya dan termasuk kejujuran sebagai salah satu karakteristik pribadi yang penting dari konselor. Kesadaran diri membantu seorang helper membentuk kejujuran terhadap dirinyaa sendiri dan terhadap konseli mereka dan juga membantu para helper menghindari, dan memperalat secara tidak bertanggung jawab atautidak etis terhadap konseli bagi kepentingan pemuasan kebutuhan pribadi konseli sendiri (Mappiare, 2011: 100).

\section{Peduli}

Kepedulian ada kaitannya dengan rasa empati kepada orang lain. Taufik (2012: 41-42) empati merupakan suatu aktivitas untuk memahami apa yang sedang dipikirkan dan dirasakan oleh yang bersangkutan (observer, perceiver) terhadap kondisi yang sedang dialami oleh orang lain, tanpa yang bersangkutan kehilangan kontrol dirinya.

Empati adalah atribut pada diri konselor yang sangat penting dan sangat berpengaruh terhadap hasil konseling (Chung \& Bemak, 2002; DeGeorge \& Constantino, 2012; Rogers, 1957; Rogers, 1975). Rogers juga mengemukakan bahwa empati dipercaya sebagai aspek yang menarik dari interaksi manusia pada umumnya dan sebagai komponen utama dari profesi bantuans pada khususnya (Myers, 1999: 141-152).

Rogers (1961: 34) mendefinisikan empati sebagai kemampuan konselor untuk memasuki dunia konseli. Empati sebagai kemampuan konselor untuk ikut merasakan apa yang dirasakan konseli (Capuzzi \& Gross, 2007: 9). Rogers menyatakan bahwa empati ini tidak hanya menyampaikan perasaan yang dirasakan konselor melalui kata-kata, akan tetapi juga mengekspresikan pengalaman konseli (Brodley, 1996: 1-10).

Komalasari,dkk (2011: 269) empathy atau deep understanding adalah 
kemampuan konselor untuk memahami permasalahan konseli, melihat melalui sudut pandang konseli, pekat terhadap perasaan-perasaan konseli, sehingga konselor mengetahui sebagaimana konseli merasakan perasaannya. Kemampuan empati konselor pada konseli diejawantahkan dalam Gambar 4.2.

Gambar 1 menunjukkan bagaimana konselor bertindak empatik kepada konselinya. Suatu saat konselor (a) memasuki dunia pribadi konseli $\left(a_{1}\right)$, namun dia tidak berubah menjadi konseli (b). Pada saatnya dia ke luar lagi menjadi dirinya sendiri $\left(\mathrm{a}_{2}\right)$.

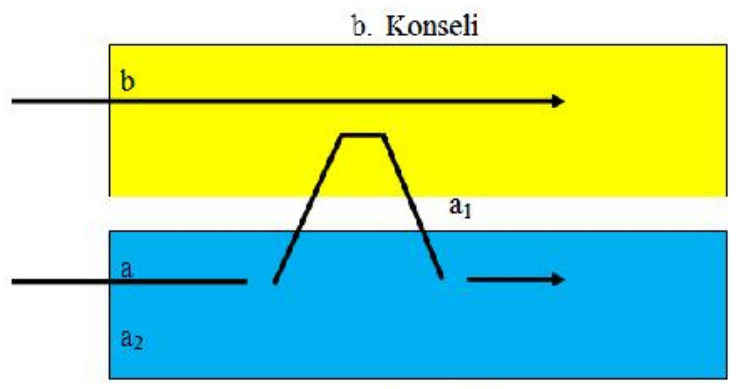

a. Konselor

Gambar 4.2 Empati Konselor Pada Konseli (Triyono, 2008: 9)

\section{Label dan Deskripsi Teknik Untuk Mengomunikasikan Sikap Dasar Konselor}

\section{Teknik Nasihat}

Teknik untuk mengomunikasikan sikap dasar konselor menggunakan teknik advice/nasihat. Doyle (1998: 231) memberikan nasihat harus dengan tujuan yang jelas. Namun, respon memberikan nasihat dapat bervariasi yaitu, dengan direktif (dinyatakan dalam nada tegas dalam memberikan nasihat), atau lebih ringan dan lebih permisif (disampaikan dalam peran yang sangat hangat).

Memberikan nasihat dilakukan dalam tahap ketiga dan keempat dari proses konseling, lebih tepatnya setelah konselor mengembangkan hubungan yang solid dan mengeksplorasi isu-isu yang berkaitan dengan kepedulian konseli. Memberikan nasihat lebih dari memberikan perintah untuk memberikan tanggapan atau reaksi dari informasi yang telah dibahas sebelumnya, nasihat memiliki penilaian atau perbaikan dari informasi yang sebenarnya (Johnson, 1997; Moursund, 1990 dalam Doyle, 1998: 231).

Doyle (1998: 231) penggunaan nasihat secara langsung dalam konseling adalah kontroversial dan dapat menjadi kontraproduktif karena beberapa alasan. Pertama, bisa menggagalkan komunikasi yang efektif dengan konseli bila digunakan secara prematur atau ketika memotong dialog penting atau mengganggu membangun hubungan yang solid. Kedua, mungkin menimbulkan ketergantungan dan mendorong konseli untuk menghindari tanggapan yang mengganggu mereka ketika mereka belajar untuk menangani persoalan-persoalan yang penting. Ketiga, dapat meningkatkan pertahanan ketika konseli menolak nasihat kita tersebut. Keempat, dapat dengan tepat menawarkan alih tangan saat nasihat yang diperlukan oleh konseli bukan hal yang kita ketahui atau kita tidak ahli dalam hal tersebut atau saat mengajukan solusi yang mudah atau sederhana untuk masalah yang kompleks. Kelima, nasihat konselor dapat disalahartikan oleh konseli. Keenam, konseli mungkin tidak mengikuti nasihat atau alternatif yang diberikan karena mungkin mereka tidak dapat melakukan sesuatu tersebut. Dan yang terakhir, konseli mungkin tidak mendengarkan nasihat atau alternatif yang konselor berikan karena konseli mungkin tidak setuju dengan keyakinan atau pendapat tentang topik tersebut.

\section{KESIMPULAN}

Berdasarkan penelitian yang telah dilaksanakan oleh penulis di SMP BSS 
Malang, dan berdasarkan paparan data dan temuan penelitian, dapat diambil kesimpulan sebagai berikut:

Pertama, Posisi diri konselor dengan diadopsi dari teks Semaryaitu (a) penasehat, (b) penyemangat, (c) pencegah, dan (d) jujur. Kedua, Sikap dasar konselor dengan diadopsi dari teks Semar yaitu (a) ramah, (b) bijaksana, (c) jujur, dan (d) peduli. Ketiga, Teknik untuk mengomunikasikan sikap dasar konselor menggunakan teknik nasihat.

Berdasarkan hasil penelitian yang telah dilakukan, dapat diajukan saran sebagai berikut:

Pertama, bagi Asosiasi Bimbingan dan Konseling Indonesia (ABKIN) sebagai salah acuan dalam pengembangan kompetensi bimbingan dan konseling multibudaya calon konselor yang perhatian pada bimbingan dan konseling berbasis multi budaya. Kedua, bagi S1 Jurusan Bimbingan dan Konseling di Indonesia sebagai referensi untuk mengembangkan ide-ide penelitian lainnya mengenai bimbingan dan konseling berbasis multibudaya. Ketiga, bagi Akademisi/ dosen S1 Jurusan Bimbingan dan Konseling di Indonesia sebagai rujukan mengenai tokoh/kearifan lokal yang bisa dijadikan sebagai tambahan bahan ajar di matakuliah konseling multibudaya.

Keempat, bagi Konselor sebagai acuan dasar mengenai model pribadi konselor dalam bimbingan dan konseling berbasis multibudaya yang bersumber dari salah satu kearifan lokal yaitu Semar. Kelima, Mahasiswa S1 Jurusan Bimbingan dan Konseling/peneliti lain sebagai dasar untuk melakukan research lanjutan mengenai bimbingan dan konseling multibudaya dengan mengangkat tema kearifan lokal Indonesia yang beraneka ragam nan unik untuk dijadikan karya ilmiah (skripsi).

\section{DAFTAR PUSTAKA}

Ahmed, S., Wilson, B.K., Henrikson, Jr. C.R., Jones, W.W.J. 2011. What Does It Mean to Be a CulturallyCompetent Counselor? Journal for Social Action in Counseling and Psychology, Vol. 3 No. 1, Hal 1728.

Alvesson, M \& Skoldberg, K. 2000. Reflexive Methodology New Vistas For Qualitative Research. London: SAGE Publications Inc.

Asmani, J.M. 2010. Panduan Efektif Bimbingan dan Konseling Di Sekolah. Yogyakarta. Diva Press

Brodley, B. T. 1996. Empathic Understanding and Feelings in Client-Centered Therapy. The Person-Centered Journal, 3 (1): 22-30.

Capuzzi, D \& Gross, D.R. 2007. Counseling and Psychotherapy: Theories and Interventions. New Jersey: Pearson Prentice-Hall.

Chung, R. C \& Bemak, F. 2002. The Relationship of Culture and Emphaty in Cross-Culture Counseling. Journal of Counseling and Development, Vol. 8o Hal 154-159.

DeGeorge, J \& Constantino, M. J. 2012. Perceptions of Analogue Therapist Empathy as a Function of Salient Experience Similarity. Journal of Psychotherapy Integration, Vol 22 No. 1. Hal 52-59.

Doyle, R.E. 1998. Essential Skills And Stategies in the Helping Process. United State of America: Brooks/Cole Publishing Company.

Gibson, R.L \& Mitchell, M.H. 2011. Bimbingan dan Konseling. Yogyakarta. Pustaka Pelajar.

Gladding, T.S. 2009. Counseling A Comprehensive Profession. New 
Jersey: Pearson Education, Inc., Upper Saddle River.

Hikmawati, F. 2014. Bimbingan dan Konseling. Jakarta: PT RajaGrafindo Persada.

Jarvis, M. 2015. Teori-teori Psikologi: Pendekatan Modern untuk Memahami Perilaku, Perasaan, \& Pikiran Manusia. Terjemahan SPA-Teamwork. 2015. Bandung: Nusa Media.

Komalasari, G., Wahyuni, E., Karsih. 2011. Teori dan Teknik Konseling. Jakarta: Indeks.

Mappiare, A. 2011. Pengantar Konseling dan Psikoterapi, Edisi Kedua. Jakarta: PT RajaGrafindo Persada.

Mappiare, A. 2013. Tipe-tipe Metode Riset Kualitatif Untuk Eksplanasi Sosial Budaya dan Bimbingan Konseling. Malang: Elang Emas (Anggota IKAPI No:119/JTI/2010) bersama Prodi Bimbingan dan Konseling.

Mulyono, E. 2013. Belajar Hermeneutika Dari Konfigurasi Filosofis Menuju Praksis Islamic Studies. Yogyakarta: IRCiSoD.

Mulyono, S. 1978. Apa dan Siapa Semar. Jakarta: Gunung Agung MCMLXXXII.

Myers, S. 1999. Empathy: Is that What I Hear You Saying? The PersonCentered Journal, Vol. 6 No. 2 Hal 141-152.

Nelson-Jones, R. 2011. Teori dan Praktik Konseling dan Terapi, Edisi Keempat. Terjemahan Soetjipto, P.H \& Soetjipto, M.S. 2011. Yogyakarta: Pustaka Pelajar.

Palmer, R.E. I969. Hermeneutics. Evanston: Northwestern University Press.

Rahardjo, M. 2008. Hermeneutika Gadamerian Kuasa Bahasa dalam
Wacana Politik Gus Dur. Malang: UIN-Malang Press.

Rivera, E. T., Phan, L.T., Maddux, C.D., Wilbur, J.R., Arredondo, P. 2006. Honesty in Multicultural Counseling: A Pilot Study of the Counseling Relationship. Interamerican Journal of Psychology, Vol. 40 No.1 Hal 3745 .

Rogers, C. R. 1957. The Necessary and Sufficient Conditions of Therapeutic Personality Change. Journal of Consulting Psychology, Vol. 21 Hal 95-103.

Rogers, C. R. 1961. On Becoming Person: A Therapist's View of Psychotherapy. London. Constable.

Rogers, C. R. 1975. Empathic: An Unappreciated Way of Being. The Counseling of Psychologist, Vol. 5 Hal 2-10.

Sardiman, A.M. 2011. Interaksi \& Motivasi Belajar Mengajar. Jakarta: PT Rajagrafindo Persada.

Shertzer, B \& Stone, S. C. 1980. Fundamentals of Counseling Boston : Houghton Mifflin Company.

Sumukti, T. 2006. Semar Dunia Batin Orang Jawa. Yogyakarta: Galang Press.

Taufik. 2012. Empati Pendekatan Psikologi Sosial. Jakarta: PT RajaGrafindo Persada.

Triyono. 2008. Memaknai Bahasa Tubuh Dalam Konseling Humanistik: Kajian Pengaruh Budaya Jawa. Bimbingan dan Konseling Jurnal Teori dan Praktik, Vol. 18 No. 2 Hal. 9. 